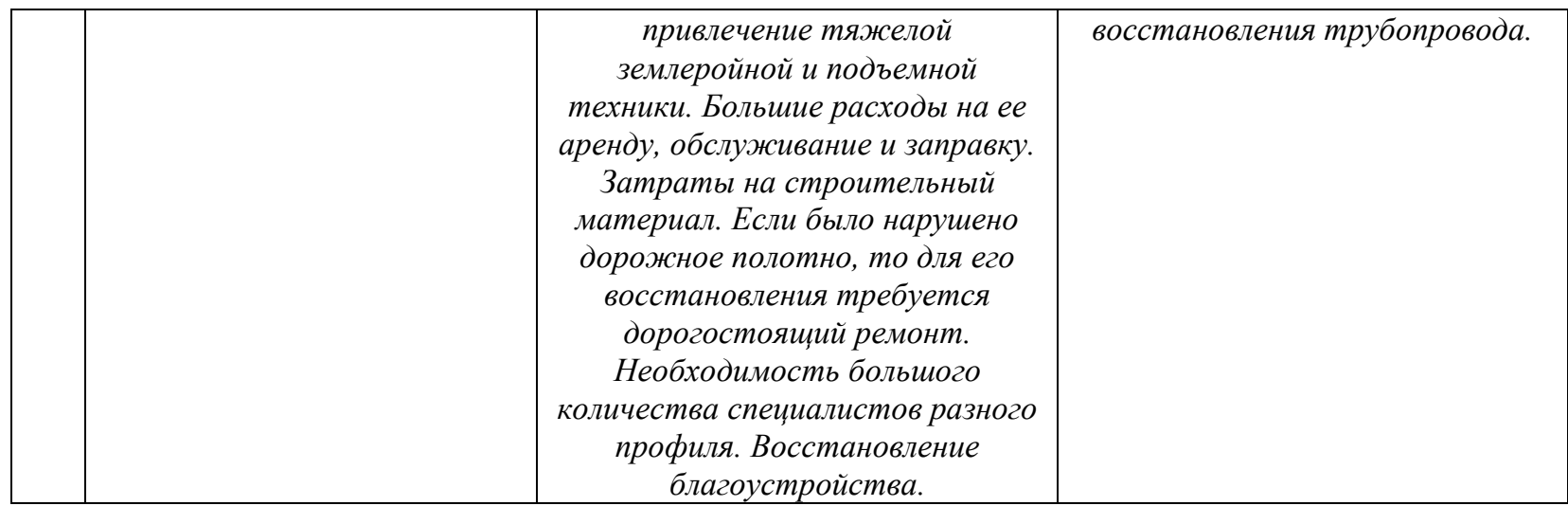

Вывод: При сравнение открытого и бестраншейного метода восстановление трубопровода были выявлены плюсы и минусы каждого метода. На смену старых методов приходят новые и поэтому актуальность применения бестраншейных технологий объясняется неуклонным ростом объемов по освоению подземного пространства, развитием инфраструктуры мегаполисов, ежегодным увеличением объемов по замене трубопроводов подземных инженерных коммуникаций. Появление новых методов решения по восстановление трубопроводов помогут справиться с возникающими затруднениями, а также с сокращением экономических затрат.

$$
* * *
$$

1. Орлов В.А., Орлов Е.В., Зверев П.В. Технологии местного бестраншейного ремонта водоотводящих трубопроводов // Вестник МГСУ. 2013. № 7. С. 86--95.

2. Потапов А.Д., Абрамян С.Г., Ахмедов А.М. Экореконструкция городского пространства Волгограда на принципах субурбанизации городских территорий // Вестник МГСУ. 2014. № 6. С. 105--113. DOI: 10.22227/1997-0935.2014.6.105-113

3. Marlow D., Gould S., Lane B. An expert system for assessing the technical and economic risk of pipe rehabilitation options. Expert Systems with Applications. (2015); Volume: 42 (Iss.22); pp. 8658-8668. DOI: 10.1016/j.eswa.2015.07.020.

\title{
Руденя О.М. \\ Основные виды повреждений деревянных конструкций в процессе длительной эксплуатации и методы борьбы с ними
}

Санкт-Петербургский государственный архитектурно-строительный университет doi: 10.18411/trnio-11-2021-70

(Россия, Санкт-Петербург)

\section{Аннотация}

В работе проведен анализ характерных дефектов деревянных элементов кровли многоквартирных домов послевоенной постройки города Калининград в процессе длительной эксплуатации. Выявлены закономерности появления и развития повреждений, изучены их влияния на деревянные конструкции, а также отмечены зависимости прочности древесины от вида длительно действовавшего напряженного состояния. Указаны причины, приведшие к возникновению повреждений и рекомендации по устранению и усилению конструкций.

Ключевые слова: элементы стропильной системы, характерные дефекты, влажность древесины, гидроизоляция, пароизоляция, несущая способность, силовые конструкции.

\section{Abstract}

The analysis of the characteristic defects of the wooden elements of the roof of apartment buildings of the post-war construction of the city of Kaliningrad in the process of long-term operation was carried out in the work. The regularities of the appearance and development of damages are revealed, their effects on wooden structures are studied, and the dependences of the 
strength of wood on the type of long-acting stress state are revealed. The reasons that led to the occurrence of damage and recommendations for the elimination and strengthening of structures are indicated.

Keywords: elements of the rafter system, characteristic defects, wood moisture, waterproofing, vapor barrier, load-bearing capacity, power structures.

В строительстве древесина всегда находила широкое применение. Ее используют при возведении домов, отделке фасадов, для кровли, а также в качестве опалубки, лесов, подмостей. Это самый экологичный строительный материал, и срок его эксплуатации превышает рекомендованный технической литературой до 60 лет.

Методы, позволяющие обеспечить необходимые прочностные свойства конструкций, представлены в нормативной документации. В них изложены зависимости от условий эксплуатации (микроклимат помещений), указаны особенности влияния на древесину влажности, длительность действия нагрузки, анизотропия физико-механических свойств и другие факторы.

Однако имеются различные примеры поведения древесины при эксплуатации. При соблюдении рекомендаций, указанных в нормативно-технической литературе, заданная несущая способность сохраняется в течение всего периода эксплуатации [1]. В противном случае из-за возникших повреждений механического и биологического характера в виде наличия трещин и участков гниения несущая способность уменьшается. Следовательно, сохранение конструкцией первоначальных свойств, заданных при ее изготовлении, можно назвать один из важнейших факторов, влияющих на изменение несущей способности. Деревянные конструкции могут прослужить многие годы или даже десятилетия, но при неправильном подходе к использованию данного строительного материала конструкции быстро разрушаются, что в итоге приведет к ремонту.

Кровельное покрытие и крыши являются основными частями зданий многоквартирных домов послевоенной постройки горогда Калининград, где используются деревянные элементы [2]. Подвергаясь физическому износу и другим внешним воздействиям, возникают различные неисправности и дефекты. Они разрушают не только сами конструкции, но и все здание в целом, в том числе сокращают нормативный срок службы (от 50 до 25 лет в зависимости от типа) [3]. В данной работе приведен анализ характерных дефектов кровли в домах - «хрущевках».

Стропила - это главный силовой элемент несущей конструкции крыши [4]. Увеличенный ее прогиб - дефект, который встречается наиболее часто. На фотографии (см. рис. 1) продемонстрировано разрушение данного элемента из-за значительного прогиба. К тому же в нижней (растянутой) зоне стропильной ноги наблюдается сучок, который значительно сокращает несущую способность.

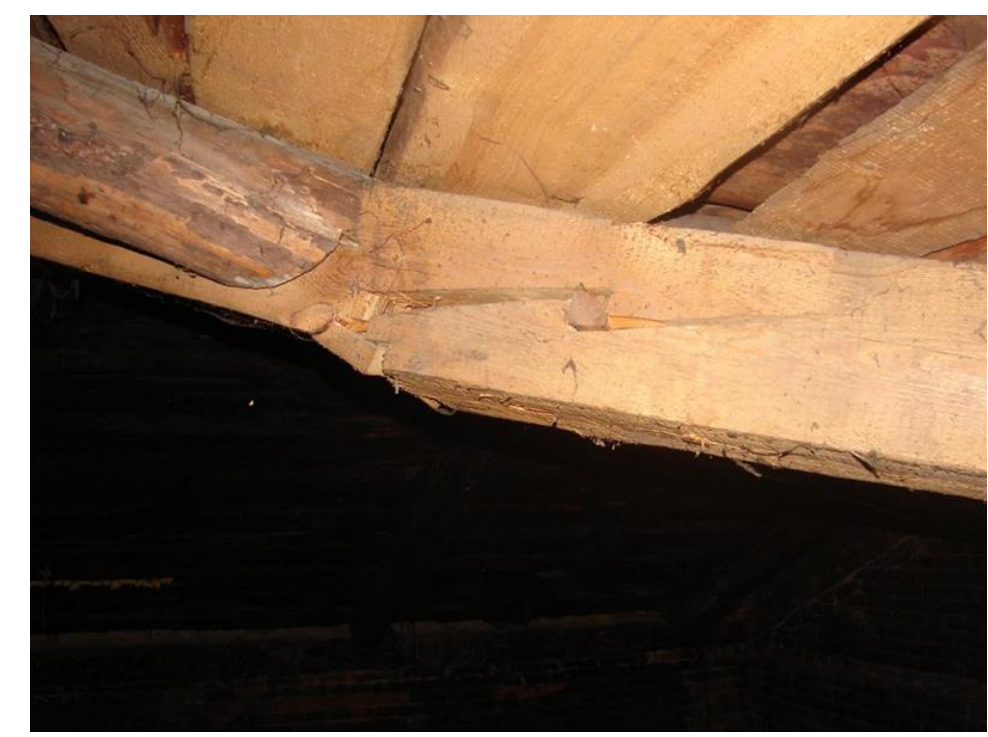

Рисунок 1. Дефект стропильной ноги из-за значительного прогиба 
Сопряжение элементов деревянных конструкций во взаимных врубках часто разрушается вследствие загнивания участков в местах, где долговременно протекала кровля (чаще всего у карнизов и в ендовах, как показано на рис. 2). Виной тому может стать отсутствие или повреждение пароизоляции и гидроизоляции, недостаточная проветриваемость чердачного помещения, отсутствие воздушных продухов либо закупоривание их концов, увлажнение древесины. Необходимо обратить внимание на слуховые окна: их размещение, площадь, на то, какая обрешетка использована (сплошная без зазоров либо разряженная) [5]. Кроме того, ввиду усушки древесины плотность прилегания элементов снижается.

Отсутствие или неполная герметизация мест сопряжений креплений кровли со стенами, парапетами и трубами приводит к порче кровельного покрытия, его вздутиям и протечкам, что в дальнейшем ведет к неизбежной порче конструкций крыши и ее ремонту.

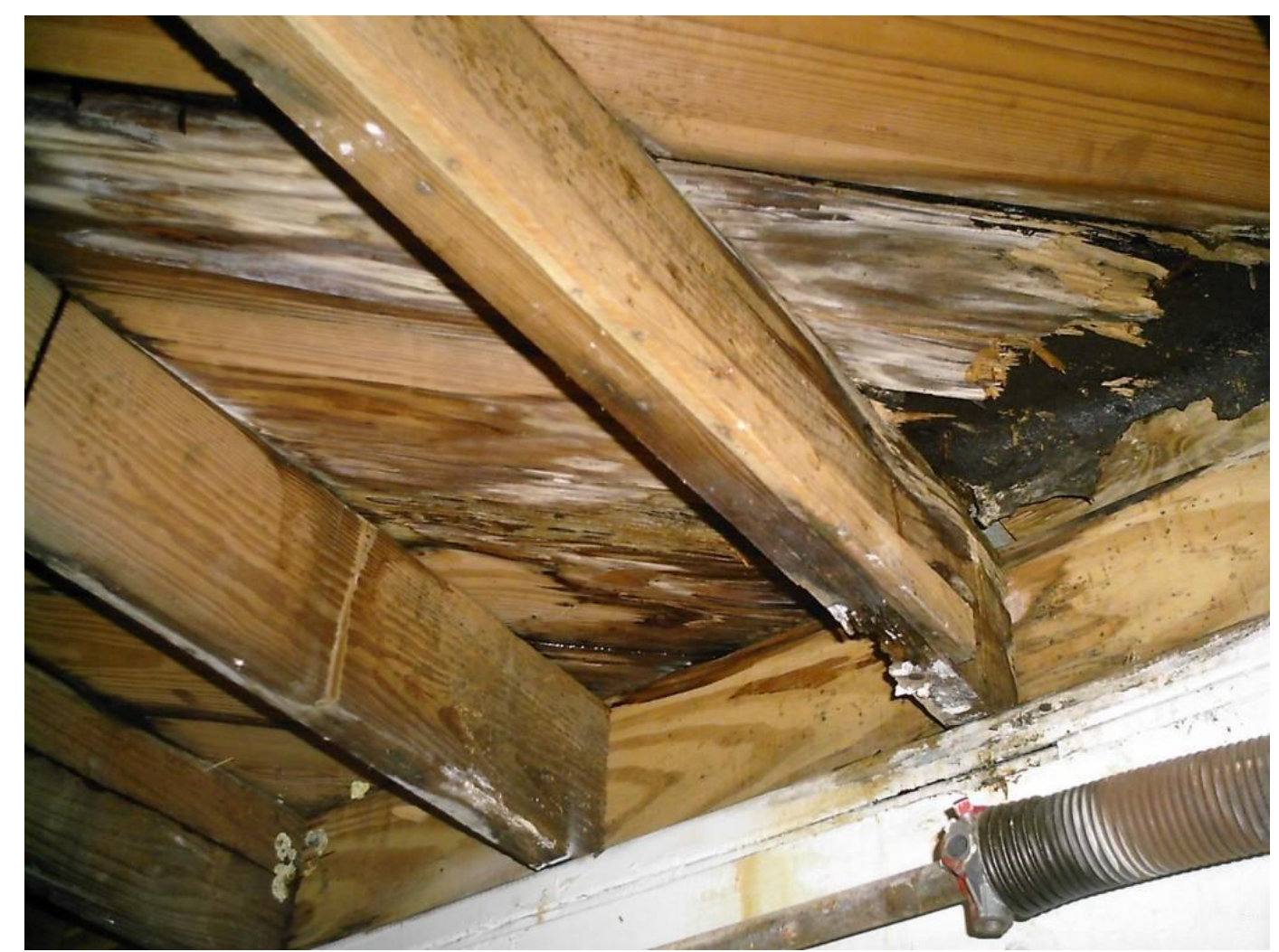

Рисунок 2. Результат протечки кровли

Причиной может стать нарушение технологии устройства сопряжения кровли с конструкцией (отсутствие планок примыкания), повреждение гидроизоляции и проникновение влаги в помещение при осадке конструкции, таяние снега на покрытие кровли или элементарно протечка после ливневого дождя.

Толщину утеплителя чердачного и кровельного перекрытия необходимо подбирать согласно рекомендациям из нормативной документации. Неудовлетворительная его толщина либо потеря должных теплозащитных свойств после долговременной эксплуатации может привести к разрушению кровли.

Для увеличения несущей способности стропильных ног как в наслонных, так и висячих стропильных системах применяют установку разгружающих балок (подмог), двухсторонних накладок и подкосов. При ремонте крыши под более крутой скат монтируют новые стропилы, сращивая их со старыми перекрестной дощатой стенкой на гвоздях. Образуется элементарная ферма, обеспечивающая нужный уклон и повышенную жесткость стропильной конструкции. 


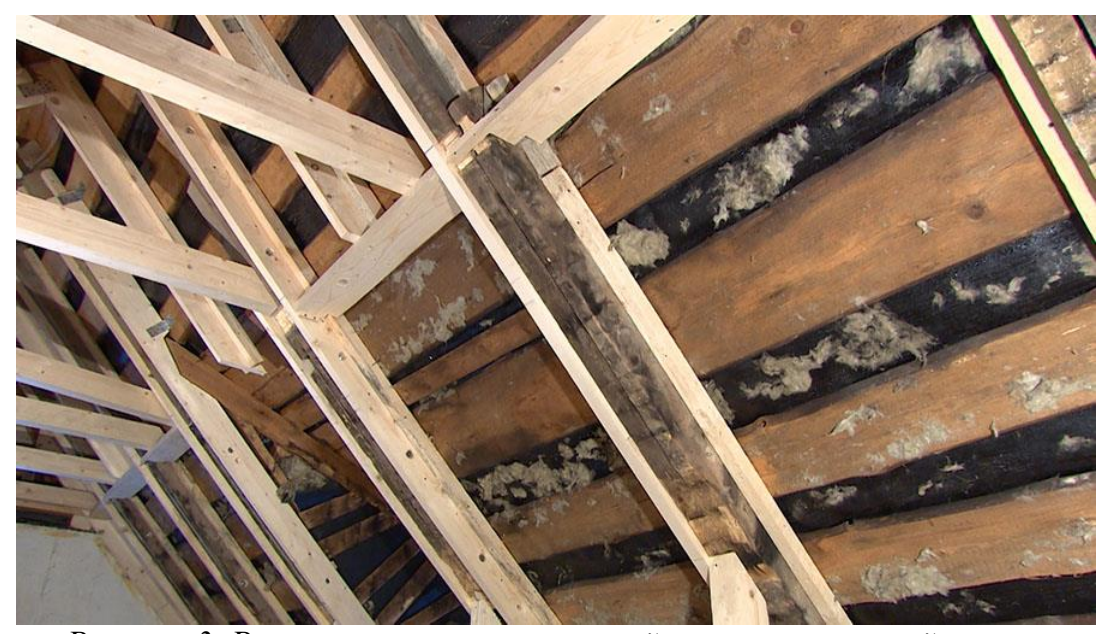

Рисунок 3. Реконструкция стропильной системы скатной крыши

Если повреждено малое количество стропил, то целесообразно использовать деревянные накладки для их укрепления. В подстропильном элементе необходимо сделать вырезы, и через них пропустить накладки. Полную площадь торца опирают на стену и устанавливают с помощью проволочной скрутки [6].

Если же повреждено большое количество стропильных ног, в таком случае применяют прутковые протезы, сделанные из стальной арматуры. Для этого необходимо демонтировать покрытие, закрепить поврежденную стропилу на временных опорах, удалить сгнивший участок методом выпиливания. Далее готовый протез надевают на стропильную ногу и устанавливают на мауэрлат. Спиленный торец стропильной ноги упирают в опорную площадку протеза, которая предотвращает ее сползание. Жесткость верхнего сжатого пояса протеза обеспечивает раскосная решетка.

При необходимости замены только сгнившего участка конца стропильной ноги и мауэрлата используют накладки, опирающиеся на балку. Первым шагом усиливают ветхую стропилу с помощью временных опор, затем вырезают сгнившие участки, устанавливают в кирпичную кладку кровельные костыли и укладывают на них балку. Накладки крепят на гвоздях с двух сторон по стропильной ноге и упирают в балку. Обрешетка держится за счет новой более длинной кобылки.

Если есть потребность замены старой кровли на новую (в большинстве случаев потребность есть) часто появляется необходимость в увеличении угла ската или несущей способности силовых конструкций.

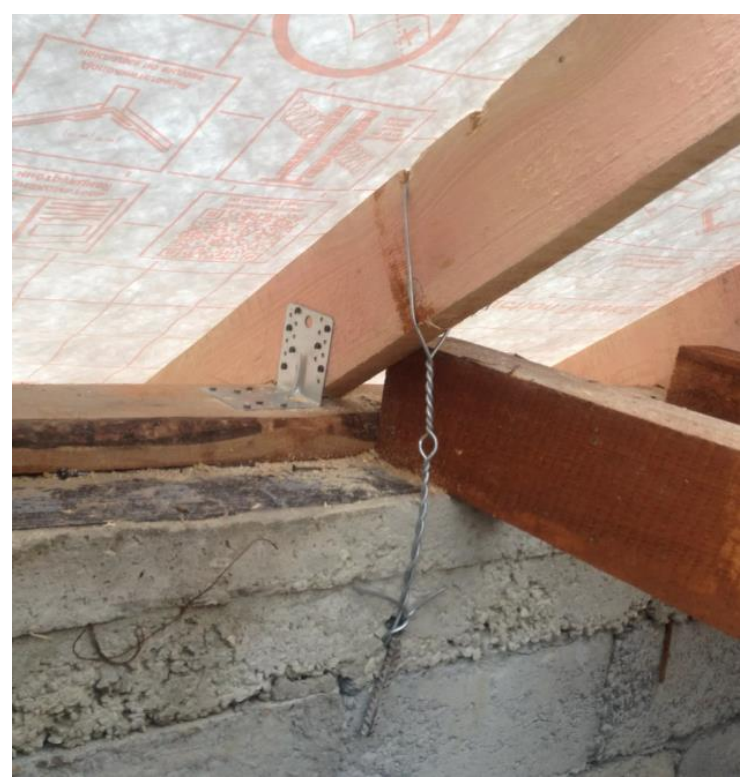

Рисунок 4. Усиление стропильных ног 
Для более долгой и качественной эксплуатации деревянных конструкций необходимо в чердачном помещении соблюдать температурный режим (не более $2^{\circ} \mathrm{C}$ ) и характер движения воздуха, увеличить количество продухов и слуховых окон [7]. Площадь сечения слуховых окон и продухов на крыше должна составлять $1 / 300-1 / 500$ площади чердачного перекрытия, то есть на каждые 1000 м2 площади чердака необходимо не менее 2 м $^{2}$ слуховых окон и продухов. Ширина продухов составляет $2-2,5$ см [8].

В случае необходимости увеличивают толщину утеплителя [9]. У наружных стен она может быть больше расчетной до 50\%. Ветхий утеплитель нужно разрыхлять раз в пять лет. Также необходимо проверить и восстановить пароизоляцию.

В местах стыков покрытия с другими элементами, к примеру, с пристройками, козырьками, дымовыми трубами и вентиляционными шахтами, кровля подвергается более интенсивным нагрузкам из-за скопления там влаги вследствие дождя и снегопада, листьев и другого мусора. При устройстве стыков выполняют их герметизацию и устанавливают закладные детали (планки примыкания) [10].

Основными контролируемыми параметрами являются прочностные характеристики древесины, а также присутствующих в строении балок, стропил, перекрытий и настилов [11]. Повышенное внимание необходимо уделять местам, которые в наибольшей степени подвергаются промерзанию или биологическому поражению. Периодическое техническое обследование деревянных конструкций здания - эффективный способ продления срока службы строения и предотвращения его полного разрушения.

На основании анализа результатов натурных обследований деревянных конструкций зданий многоквартирных домов послевоенной постройки города Калининград, длительно эксплуатируемых в различных температурно-влажностных условиях, исследования особенностей расположения биологических и механических повреждений конструкций выявлены основные закономерности развития повреждений. Наиболее значительно снижают прочность сучки, выходящие на ребро, вследствие несимметричного к оси материала расположения, перерезания волокон и попадания при работе в растянутую зону. Известно, что пороки древесины, изменяющие направление волокон (сучки, косослой, свилеватость) резки снижают прочностные свойства материала на растяжение.

Прочностные свойства древесины, отработавшей длительный срок, при сжатии и смятии со временем не претерпевают изменений, пределы прочности при изгибе, растяжении и скалывании существенно снижают свои значения, а изменение деформационных свойств происходит в зависимости от угла наклона волокон по отношению к прикладываемым усилиям.

$$
* * *
$$

1. Серов Е.Н., Серова Т.А. Миронова С.И. Реставрация деревянных конструкций в зданиях и сооружениях. Учебное пособие. СПб. СПб ГАСУ. 2018. С. 411.

2. Миронова С.И. Руденя О.М. Анализ состояния многоквартирных домов послевоенной постройки в городе Калининград. В сборнике: Инновации в деревянном строительстве. Материалы 11-й Международной научно-практической конференции. Санкт-Петербург, 2021. С. 163-167.

3. СП 255.1325800.2016 Здания и сооружения. Правила эксплуатации. Основные положения

4. СП 64.13330.2017 Деревянные конструкции

5. СП 17.13330.2017 Кровли

6. ГОСТ 11047-90 Детали и изделия деревянные для малоэтажных жилых и общественных зданий

7. СП 50.13330.2012 Тепловая защита зданий

8. СТО НОСТРОЙ 2.13.81-2012 Крыши и кровли. Требования к устройству, правилам приемки и контролю

9. СП 71.13330.2017 Изоляционные и отделочные покрытия.

10. Данилов Е.В. Инновации в деревянном строительстве. Материалы 11-й Международной научнопрактической конференции / Санкт-Петербург, 2021.

11. Миронова С.И. Снижение образования трещин на оцилиндрованных бревнах при использовании масляновосковых защитных составов. Вестник гражданских инженеров. 2015 №3 (50). Стр. 167-170 